\title{
COMPARISON OF MODIFIED METHOD OF LIGATION OF INTERSPHINCTERIC FISTULA TRACT (LIFT) AND STANDARD OPERATIONS IN PATIENTS WITH TRANSSPHINCTERIC RECTAL FISTULAS
}

\author{
Kryvoruchko I.A. ${ }^{1}$, Firsyk T.M. ${ }^{1}$, Bozhko O.P. ${ }^{2}$ \\ ${ }^{1}$ Kharkiv National Medical University of the Ministry of Health of Ukraine, Ukraine \\ ${ }^{2}$ Kharkiv Regional Clinical Hospital of the Ministry of Health of Ukraine, Ukraine
}

https://doi.org/10.35339/ic.6.2.82-87

\begin{abstract}
Background. The search for and development of new minimally invasive methods for the surgical treatment of anal fistulas is a relevant area of surgery. Such methods combine less traumatization and preservation of the sphincter's complex. Employment of such methods for surgical treatment of anal fistulas reduced the time of stay of patients in the hospital and improved their quality of life. Subjects and methods. A retro- and prospective study involved 58 patients with uncomplicated transsphincteric anal fistulas. All patients were treated in the hospital from January 2014 to April 2019. The patients were divided into two groups: the first group included 32 patients who were operated on according to the standard procedure using fistulotomy and Seton procedure; the second group consisted of 26 patients who were operated on using the modified LIFT method. Results. Most of these patients (72.4\%) were men at the age of 42.536 .79 . The median of BMI was $25.7 \mathrm{~kg} / \mathrm{m} 2$. There wasn't mortality after operations. The median follow-up was $21(6-48)$ weeks. In the first group there were 3 cases $(9.3 \%)$ of anal sphincter insufficiency and 7 cases of recurrent fistulas $(21.9 \%)$ at different times after surgery. In the second group there were no anal sphincter failure following administration of the modified method LIFT, but there were $15.4 \%$ of recurrent anal fistulas. Conclusion. The proposed modified method of ligation of intersphincteric fistula tract is an effective method for the treatment of anal fistulas. The results obtained suggest that the developed method can be used to treat other types of anal fistulas.
\end{abstract}

Keywords: transsphincteric anal fistula, surgical treatment, LIFT technique, postoperative complications.

\section{Introduction}

Rectal fistula (anal fistula, fistula-in-ano, chronic paraproctitis) is a pathological course or cavity connecting the lumen of the anal canal or rectum with the perineum. The main clinical manifestations of the disease are mucopurulent discharge in this area, pain syndrome, discomfort, which significantly reduces the patient's quality

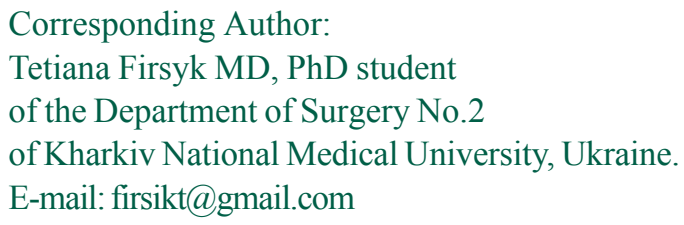

of life [1]. According to foreign literature, the prevalence of rectal fistula in European countries is $10.4-3.2$ persons per 100,000 population [2]; this disease is more common among men than in women with a ratio of 1.8: 1 [3]. Reticular fistulas are diagnosed in patients of different ages, but most often they occur in the age group of 30-50 years [4], that is, in the most able-bodied and socially active part of the population. In 2016 in Sweden, Lundqvist A. et al. conducted a study to evaluate the cost of rectal fistulas treatment in 362 patients. The authors have shown that the total cost of patient treatment amounted to an average of 5561 euros, of which $80 \%$ were direct 
medical expenses for treatment. The remaining $20 \%$ were economic losses associated with the duration of the period of disability, an average of 10.4 days [5]. It should be noted that such a high cost of treatment was due to the high number of recurrences and development of complications.

Rectal fistulas rank fourth in the structure of proctological diseases. This disease can be treated only surgically. Among all proctologic operations, from 13.6 to $25.4 \%$ of operations to eliminate fistulas are performed each year $[6,7]$. The most common cause of perianal fistula is inflammation of the anal glands in the anal crypt area, followed by the spread of infection to the adrectal tissue. The infection can also penetrate through the damaged lymphogenous and hematogenous rectal mucosa. Chronic recurrent anal fistulas are due to the lining of the internal hole of the fistula with the glandular epithelium of the anal glands and the subsequent complete or partial epithelization of the lumen of the fistulous passage, preventing its spontaneous healing.

There are more than one hundred methods of surgical treatment of fistulas of the rectum, but there is still no single "gold standard". The main components of the surgical treatment of fistulas are the excision of the fistulous course, the elimination of purulent infections and the provision of wound healing [8-12]. Considering the involvement of the anal sphincter in the pathological process, the most important is the preservation of its functional ability. That is why the search for new minimally invasive methods of surgical treatment remains relevant.

\section{Purposes, subjects and methods:}

2.1. Purpose - was to compare and to analyze the standard methods of surgical treatment of anal fistulas with the modified method of ligation of intersphincteric fistula tract (LIFT) that we developed in our clinic.

\subsection{Subjects \& Methods}

A retro- and prospective study involved 58 patients with uncomplicated transsphincteric anal fistulas. All patients were treated in the hospital from January 2014 to April 2019. The patients were divided into two groups. The first group included 32 patients who were operated with the standard methods. The standard procedures included fistulotomy and Seton techniques. The second group (the remaining 26 patients) were operated with the modified method LIFT.

Identification of patients, operative technique and postoperative period

The inclusion criterion was the diagnosis of transsphincteric anal fistulas. In all patients, this diagnosis was made for the first time. Exclusion criteria were the presence of surface fistulas, as well as fistulas associated with Crohn's disease. Patients with concomitant pathology of the rectum were excluded from the study.

After the diagnosis was made, the patients underwent laboratory and instrumental examinations. Laboratory methods included standard tests and bacteriological examination of purulent contents of the fistula. Instrumental examination methods included anoscopy, rectoromanoscopy, fistulography and MRI. Preliminary identification of the fistulous course was necessary to define the localization of the fistula. It also helped to determine the presence of purulent cavities. The patients diagnosed with uncomplicated fistulas were included in the study.

The proposed method is a modification of the classical technique of LIFT. First the fistulous duct was contrasted. Then the distal part of the fistula was excised at the probe. Then a probe was inserted through the internal opening of the fistulous passage and a fistula was fixed on it. After that, the intra sphincter part of the fistula was inverted into the rectal lumen and ligated closer to the intestinal mucosa. The operation was performed under spinal anesthesia. An antibacterial prophylaxis was administered for 24 hours.

In the postoperative period all patients received analgesics and syrups softening feces. Postoperative care included the use of antiseptic baths, dressing with ointment and rectal suppositories. We have identified main parameters in order to compare the results of surgical treatment. There were such parameters as recurrence of the disease, functionality of the anal sphincter, terms of wound healing, days at the hospital stay. The procedure was considered successful in complete wound healing, absence of insolvency of the anal sphincter or recurrence of the disease. In the event of fistula recurrence the result of treatment was regarded as unsatisfactory. Postoperative complications and mortality were evaluated in all the examined patients.

In order to assess the quality of treatment, all patients underwent follow-up examination. Similar examinations were carried out every 2 weeks after discharge from the hospital in the first two months after surgery. After that monitoring of the results of surgical treatment was carried out for 3 to 12 months. We conducted a survey and clinical examinations of patients at each visit in order to clarify presentation and complications.

Conflict of interests. There is no conflict of interests. 


\section{Results and discussion}

The characteristics of patients who were studied are presented in the Tables 1 and 2. The first group included 23 men (71.8\%) and 9 women
(31.2\%) out of 32 operated. Of these, 7 (21.9\%) patients had a recurrence of the disease and other 3 patients had sphincter deficiency in all periods of observation. Postoperative

Table 1

Characteristics of patients who participated in the study

\begin{tabular}{|l|l|}
\hline \multicolumn{1}{|c|}{ Characteristics under investigation } & \multicolumn{1}{c|}{ Indicators obtained } \\
\hline Number of patients & 58 \\
\hline Males $(\%)$ & $42(72.4 \%)$ \\
\hline Females (\%) & $16(27.6 \%)$ \\
\hline Average age & $42.53 \pm 6.79$ \\
\hline Median BMI $\left(\mathrm{kg} / \mathrm{m}^{2}\right)$ & 25.7 \\
\hline Accompanying diseases $(\%)$ & $9(15,5 \%)$ \\
\hline Previous operations $\left(1^{\text {st }} / 2^{\text {nd }}\right)$ & $7(4 / 3)$ \\
\hline $\begin{array}{l}\text { Type of fistula }(\%) \text { and the complexity of the fistula } \\
\text { in groups (simple } / \text { complex) }\end{array}$ & 58 patients $(100 \%): 1^{\text {st }}-8 / 24 ; 2^{\text {nd }}-7 / 19$ \\
\hline $\begin{array}{l}\text { Distance between the external hole of the fistula } \\
\text { and the anus }(\mathrm{cm})\end{array}$ & $4.5 \pm 0,93$ \\
\hline
\end{tabular}

Table 2

Grouping by sex and age

\begin{tabular}{|l|c|c|c|c|c|c|c|c|}
\hline \multirow{2}{*}{$\begin{array}{c}\text { Age } \\
\text { of patients }\end{array}$} & \multicolumn{4}{|c|}{ First group (n=32) } & \multicolumn{4}{c|}{ Second group (n=26) } \\
\cline { 2 - 9 } & \multicolumn{2}{|c|}{ Males } & \multicolumn{2}{c|}{ Females } & \multicolumn{2}{c|}{ Males } & \multicolumn{2}{c|}{ Females } \\
\cline { 2 - 9 } & Per. & $(\%)$ & Per. & $(\%)$ & Per. & $(\%)$ & Per. & $(\%)$ \\
\hline $25-44$ & 9 & 28.12 & 2 & 6.25 & 7 & 26.92 & 3 & 11.53 \\
\hline $45-60$ & 11 & 34.37 & 5 & 15.64 & 8 & 30.76 & 3 & 11.53 \\
\hline $61-70$ & 3 & 9.37 & 2 & 6.25 & 4 & 15.38 & 1 & 3.88 \\
\hline Total & 23 & 71.86 & 9 & 28.14 & 19 & 73.06 & 7 & 26.94 \\
\hline
\end{tabular}

$(28.2 \%)$, the second group comprised 19 men $(73.1 \%)$ and 7 women $(26.9 \%)$. The age of the patients was $42.53 \pm 6.79$, mean body mass index (BMI) was 25.7, concomitant diseases were noted in $9(15.5 \%)$ patients. In the first group of patients, simple fistulas were diagnosed in 8 and complex in 24 patients, and in the second group, 7 and 19 patients, respectively. The distance between the external opening of the fistula and the anus was $4.5 \pm 0.93 \mathrm{~cm}$.

Among the patients in the first group 23 $(71.8 \%)$ patients underwent excision of the anal fistula with admissible sphincterotomy without disturbance the function of the closure of the sphincter complex of the rectum. In 8 of these patients the operations was supplemented with sphincteroplasty. The remaining 9 patients (28.2\%) underwent Seton techniques of the anal fistula. After evaluating the results of surgical treatment of patients from the first group, $84.4 \%$ of cases were found to be satisfactory. The result of treatment was unsatisfactory in 10 patients complications were observed in 4 patients $(12.5 \%)$. All complications were resolved with the help of conservative treatment. The patients of the second group were operated with the modified method of LIFT. Treatment was satisfactory in 22 patients $(84.6 \%)$. Anal fistula recurred in 4 patients $(15.4 \%)$. Anal sphincter insufficiency was not registered in this category of patients. Two patients had complications in postoperative period $(7.7 \%)$. These complications were also resolved with the help of conservative treatment methods.

All the results of treatment for all 58 patients are shown in the Tables 3 and 4.

As can be seen from the Table 4, patients operated with modified method LIFT reduced the days of hospital stay. The postoperative hospital stay of such patients averaged 12.3 days.

In such patients, the healing time of the wound was also shorter. The average duration was 26.1 days. This can be explained by the less traumatic nature of the proposed method. 
Table 3

Comparative results of treatment

\begin{tabular}{|l|c|c|}
\hline \multirow{2}{*}{ Comparative parameters } & \multicolumn{2}{|c|}{ Results } \\
\cline { 2 - 3 } $\begin{array}{l}\text { Operation duration, minutes } \\
\text { (median, min, max) }\end{array}$ & Standard methods & LIFT \\
\hline Satisfactory result of treatment (\%) & $50.5(39-72)$ & $49.6(35-67)$ \\
\hline Recurrence of fistulas (\%) & $84.4 \%$ & $84.6 \%$ \\
\hline Sphincter deficiency (\%) & $7(21.9 \%)$ & $4(15.4 \%)$ \\
\hline Postoperative complications & $3(9.4 \%)$ & $2(7.7 \%)$ \\
\hline Postoperative mortality & $4(12.5)$ & 0 \\
\hline $\begin{array}{l}\text { Observation after surgery, weeks } \\
\text { (median, min, max) }\end{array}$ & 0 & $18(2-48)$ \\
\hline $\begin{array}{l}\text { Time of fistula recurrence, month } \\
\text { (median, min, max) }\end{array}$ & $24(2-48)$ & $18(8-24)$ \\
\hline
\end{tabular}

Table 4

Comparative results of surgical treatment

\begin{tabular}{|c|c|c|c|c|}
\hline \multirow{3}{*}{$\begin{array}{c}\text { Comparative } \\
\text { parameters }\end{array}$} & \multicolumn{4}{|c|}{ Groups of patients } \\
\hline & \multicolumn{3}{|c|}{$1^{\text {st }}(\mathrm{n}=32)$} & \multirow{2}{*}{$\frac{\mathbf{2}^{\text {nd }}(\mathbf{n}=\mathbf{2 6})}{\text { LIFT }}$} \\
\hline & Sphincterotomy & $\begin{array}{l}\text { Sphincterotomy with } \\
\text { sphincteroplasty }\end{array}$ & $\begin{array}{c}\text { Seton } \\
\text { technique }\end{array}$ & \\
\hline Number of patients & 15 & 8 & 9 & 26 \\
\hline Operation duration (min) & 48.1 & 55.8 & 58.4 & 49.6 \\
\hline Recurrence of fistulas & 3 & 2 & 2 & 4 \\
\hline Sphincter deficiency & 1 & 1 & 1 & 0 \\
\hline Terms of wound healing (days) & 29.7 & 27.4 & 41.4 & 26.1 \\
\hline Days of the hospital stay & 14.2 & 13.7 & 17.1 & 12.3 \\
\hline Postoperative mortality & 0 & 0 & 0 & 0 \\
\hline
\end{tabular}

If simple anal fistulas do not present great difficulty in diagnosis and treatment, and also accompanied by a small percentage of complications after surgery, complicated fistula is a frequently discussed topic in clinical practice. Many surgical methods have been described for the treatment of such anal fistulas, including Seton technique, fibrin glue, collagen closures, rectal valves, fistulotomy with regeneration of the sphincter and redirecting the fistulous tract [13]. However, the results were variable and no procedure exceeds the other altogether. It is worth worrying that the purpose of any treatment is to destroy the path and reduce the frequency of relapses while maintaining the full functionality of the anal sphincter complex. The fistulotomy opens the fistula path, leaving less wounds without epithelization, which accelerates healing of the wound. Currently, fistulotomy is still the most widely used method. But the high rate of treatment is limited by the fact that the incidence of fetal incontinence can be up to $40 \%$ [14] when transphasic fistula is opened and the internal and external sphincter is cut. The most important factor when choosing an adequate method of operation is known to be the relationship of the fistulous passage to the fibers of the sphincter apparatus of the rectum. The most reliable method of surgical treatment of complex fistulas is its excision or dissection into the lumen of the rectum. Sphincterotomy is an effective way to treat anal fistulas. But if the fistula spreads to most of the sphincter complex, the operation may contribute to insolvency of the anal sphincter in the postoperative period. In the surgical approach to dissection/excision of the fistula, some authors take into account the degree of involvement of the sphincter apparatus by no more than $10-20 \%$; others no more than $33 \%$. Therefore, this operation requires appropriate selection of patients.

In 2007, Rojanasakul et al. described a new surgical variant for such cases with very good 
initial results. Since then, LIFT has been used as a remedy for sphincter, to restore anal fistulas through early satisfactory results. Today there are more than 6 variants of the LIFT. However, the success rate varies from 47 to $95 \%[15,16]$. This can be explained by the fact that some methods are based only on ligation of the fistulous tract without its excision. There was no comparative study between the methods at this time. That is why it is difficult to determine the true value of both the classic technique and its modifications. We are confident that the success of the operation depends on the identification of the fistulous tract and its excision. It should also be noted that the excision of the fistulous tract in the intersphincteric space reduces the risk of development of the anal sphincter deficiency. Since direct comparison between technical variants was not made, it remains difficult to find out the true effectiveness of the classic LIFT or any of its technical varants [17]. Thus, the technique of LIFT without incision of the fistula is a minor modification of the operation [8]. The indicator of success in $47-94.2 \%$ was reported using this LIFT technique [18]. We are convinced that success after this operation depends on the proper identification of the fistula and the processing of its distal part without damage, as well as the reliable treatment of the internal hole of the fistula. Currently, there may be some controversy over the definition of failure after surgery, persistence and recurrence of anal fistula after surgery. In any case, success after the LIFT procedure can be objectively defined as complete postoperative healing, both the fistula outlet and the wound between sphincters. Finally, recurrence can be considered as a recurrence of fistula after complete healing of the wound [19].

In our study, there were 3 cases $(9.3 \%)$ of anal sphincter failure with the use of fistulotomy and Seton technique and 7 cases of recurrent fistulas $(21.9 \%)$ after these interventions at different times after surgery. The modified LIFT technique was not associated with any anal sphincter failure, but $15.4 \%$ of recurrent anal fistulas were observed in these patients. We analyzed the results and identified the main causes of recurrence and insufficiency of the anal sphincter. The first group included mistakes associated with preoperative diagnosis. Incomplete fistula contrasting contributes to incorrect determination of the course of the fistula relative to the fibers of the anal sphincter. This is why some authors recommended using MRI [20] which we used before the operation only in 3 patients of the second group. This method helps to determine purulent pararectal foci, and also get the complete information on the condition of the anal sphincter complex and guarantees the correct choice of surgical procedures. Among the technical mistakes we noted two main ones. Firstly, excessive excision of the anal sphincter tissue during fistula discharge. Secondly, wound suppuration which contributes to the failure of the sutures. These factors lead to the formation of a coarse postoperative scar that reduced the functional ability of the sphincter.

Some authors suggested the use of drainage before the LIFT procedure as an effective remedy for failure after surgery, although this was not mentioned in the original descriptive publication. But studies show that previous use of drainage before LIFT did not affect the performance indicators and in analyzing the combined data of four studies of patients undergoing LIFT with preoperative drainage and without it, no significant difference was observed with the previous drainage [21, 22]. Nevertheless, the results presented should be interpreted with caution since in some cases the initial design of the study was not aimed at studying or comparing the results of patients with or without drainage.

We achieved $84.6 \%$ of successful wound healing after the modified method of LIFT. We consider this technique promising since its implementation does not require expensive materials. It is necessary to continue research on the modified method of LIFT. This will help to identify shortcomings and also help to improve the methods of surgical treatment with complex transsphincteric fistulas of the rectum.

Conclusions. Minimally invasive surgical methods are a promising direction in proctology. The modified technique LIFT is an effective method of surgical treatment of transsphincteric fistulas of the rectum. The operation that we proposed is simple to perform. It does not require the use of expensive materials and therefore, this method is profitable with economic component. The advantage of the method is to preserve the quality of life. A high level of successful operations indicates the prospect of use of this method in the treatment of fistulas of other types.

\section{References}

1. Alasari, S., Kim N.K. Overview of anal fistula and systematic review of ligation of the intersphincteric fistula tract (LIFT) (2014). Tech. Coloproctol., 18 (1), 13-22. http://dx.doi.org/10.1590/01026720201700040002 
2. Zanotti, C. An assessment of the incidence of fistula-in-ano in four countries of the European Union (2007). Int. J. colorectal Dis., 22 (12) , 1459-1462. doi: 10.1007/s00384-007-0334-7.

3. Cadeddu, F., Salis F., Lisi G., Ciangola I., Milito G. Complex anal fistula remains a challenge for colorectal surgeon (2015). Int. J. Colorectal Dis., 30 (5), 595-603.

4. Zawadzki A., Starck M. Collagen plugs a new treatment of complex anal fistulas. Experiences from a Swedish center (2008). Lakartidningen, 105 (20), 1489-1491. PMID: 18575404

5. Lundqvist A., Ahlberg I., Hjalte F., Ekelund M. Direct and indirect costs for anal fistula in Sweden (2016). Int. J. Surg., 35, 129-133. doi: 10.1016/j.ijsu.2016.09.082.

6. Aboulian A., Kaji A.H., Kumar R.R. Early result of ligation of the intersphincteric fistula tract for fistula-in-ano (2011). Dis. Colon Rectum, 54 (3), 289-292. doi: 10.1007/DCR.0b013e318203495d.

7. Amato A., Bottini C., De Nardi P., Giamundo P., Lauretta A., Realis Luc A., Tegon G., Nicholls R.J. Evaluation and management of perianal abscess and anal fistula (2015). Tech. Coloproctol., 19(10), 595-606. doi: 10.1007/s10151-015-1365-7.

8. Rojanasakul A., Pattanaarun J., Sahakitrungruang C. Total anal sphincter saving technique for fistula-in-ano; The ligation of 12 intersphincteric fistula tract (2007). Journal of the Medical Association of Thailand, 90 (3), 581-586. PMID: 17427539.

9. Shanwani A., Nor A.M., Amri N. Ligation of the intersphincteric fistula tract (LIFT): a sphinctersaving technique for fistula-in-ano (2010). Dis. Colon Rectum, 53, 39-42. doi: 10.1007/ DCR.0b013e3181c160c4.

10. Sirikurnpiboon S., Awapittaya B., Jivapaisarnpong P. Ligation of intersphincteric fistula tract and its modification: Results from treatment of complex fistula (2013). World J. Gastrointest. Surg., 5, 123128. doi: 10.4240/wjgs.v5.i4.123.

11. Song Ho K. New technique for treating anal fistula (2012). Journal of the Korean Society of Coloproctology, 28(1), 7-12. doi: https://doi.org/10.3393/jksc.2012.28.1.7

12. Wong S., Solomon M., Crowe P., Ooi K. Cure, continence and quality of life after treatment for fistula-in-ano (2008). ANZ Journal of Surgery, 78(8), 675-682. doi: 10.1111/j.1445-2197.2008.04616.x.

13. Rizzo J. A., Naig A. L., Johnson E. K. Anorectal abscess and fistula-in-ano: evidence-based management (2010). Surgical Clinics of North America, 90(1), 45-68. doi: 10.1016/j.suc.2009.10.001.

14. Han J. G., Yi B. Q., Wang Z. J., et al. Ligation of the intersphincteric fistula tract plus a bioprosthetic anal fistula plug (LIFT-Plug): a new technique for fistula-in-ano (2013). Colorectal Disease., 15(5), 582586. doi: 10.1111/codi.12062.

15.Wallin U. G., Mellgren A. F., Madoff R. D., Goldberg S. M. Does ligation of the intersphincteric fistula tract raise the bar in fistula surgery? (2012). Diseases of the Colon and Rectum., 55(11), 11731178. doi: 10.1097/DCR.0b013e318266edf3.

16.Limura E., Giordano P. Modern management of anal fistula ( 2015). World J. Gastroenterol., 21, 12-20. doi: 10.3748/wjg.v21.i1.12.

17. Mushaya C., Bartlett L., Schulze B., Ho Y.H. Ligation of intersphincteric fistula tract compared with advancement flap for complex anorectal fistulas requiring initial seton drainage (2012). Am. J. Surg., 204 (3), 283-289. doi: 10.1016/j.amjsurg.2011.10.025.

18. Liu W.Y., Aboulian A., Kaji A.H., Kumar R.R. Long-term results of ligation of intersphincteric fistula tract (LIFT) for fistula-in-ano (2013). Dis. Colon Rectum, 56, 343-347. doi: 10.1097/ DCR.0b013e318278164c.

19. Campbell M.L., Abboud E.C., Dolberg M.E., Sanchez J.E., Marcet J.E., Rasheid S.H. Treatment of refractory perianal fistulas with ligation of the intersphincteric fistula tract: preliminary results (2013). Am. Surg., 79, 723-727. PMID: 23816007.

20. Pomerri F. Anal endosonography and fistulography for fistula-in-ano (2010). Radio Med., 115(5), $71-83$.

21. Meinero P., Mori L. Video-assisted anal fistula treatment (VAAFT): a novel sphincter-saving procedure for treating complex anal fistulas (2011). Tech. Coloproctol., 15, 417-422. doi: 10.1007/ s10151-011-0769-2.

22. Araujo S.E.A., Marcante M. T., Mendes C. R. S., Bertoncini A. B., Seid V. E., Horcel L. A., Perez R. O., Klajner S. Interesfincterial ligation of fistula tract (LIFT) for patients with anal fistulas: a brazilian bi-institutional experience (2017). ABCD Arq Bras Cir Dig., 30(4), 235-238. doi: 10.1590/01026720201700040002 . 